Ren, X., Zhu, Z. and Chen, Z. (2017). "Automatic monitoring of operating equipment efficiency for air pollutant emission estimation.” In: LC3 2017: Volume I - Proceedings of the Joint Conference on Computing in Construction (JC3), July 4-7, 2017, Heraklion, Greece, pp. 579-586. DOI: https://doi.org/10.24928/JC3$\underline{2017 / 0207 .}$.

\title{
AUTOMATIC MONITORING OF OPERATING EQUIPMENT EFFICIENCY FOR AIR POLLUTANT EMISSION ESTIMATION
}

\author{
Xiaoning Ren ${ }^{1}$, Zhenhua $\mathrm{Zhu}^{2}$ and Zhi Chen ${ }^{3}$
}

\begin{abstract}
Construction activities are considered as one of the major air pollutant emissions sources. Specifically, construction equipment produces a large share of the emissions, including carbon oxides, nitrogen oxides, etc. on construction sites. Therefore, it is necessary to monitor and control the operating efficiency of the onsite equipment in order to reduce the amount of its air pollutant emissions. However, the current practices for monitoring and measuring the operating equipment efficiency is heavily dependent on the practitioners' observations. It is labour-intensive and timeconsuming. The main objective of this paper is to present a novel method for automatically monitoring the operating equipment efficiency (OEE) with the fusion of visual and thermal data. Under the method, construction equipment is firstly located and tracked in the visual and thermal data. Based on the locating and tracking results, the equipment value-added activities are identified to determine its valuable operating time. Moreover, the total operating time is determined by checking the duration of the equipment with the running engine. This way, the OEE can be measured as the ratio of the valuable operating time over the total operating time. The method has been tested on the construction site of Poste De Lorimier in Montreal. The test results indicate its effectiveness.
\end{abstract}

Keywords: Operating equipment efficiency; Automation; Video analysis; Thermal data; Air pollutant emissions.

\section{INTRODUCTION}

According to the U.S. Environmental Protection Agency (USEPA), the construction industry sector is ranked as the third largest Greenhouse Gas (GHG) emission contributor, which accounts for $6 \%$ of total GHG emissions among all industrial sectors in US (USEPA 2009). Also, it generates a large quantity of other diesel exhaust emissions, such as carbon monoxide $(\mathrm{CO})$, nitrogen oxides $\left(\mathrm{NO}_{\mathrm{x}}\right)$, volatile organic compounds $(\mathrm{VOC})$, and particulate matter (PM) (USEPA 2008). In particular, approximate 1,578,000 tons of NOx, 866,700 tons of $\mathrm{CO}, 177,5000 \mathrm{SO}_{2}$, and 165,200 tons of $\mathrm{PM}_{10}$ were emitted from construction vehicles in 2002 (USEPA 2005). In 2006, 32\% of the $\mathrm{NO}_{\mathrm{x}}$ emissions and $37 \%$ of the PM emissions from fuel-based engines were emitted from construction equipment. Therefore, many

1 Graduate Student, Department of Building, Civil, and Environmental Engineering, Concordia University, Montreal, Canada, H3G 1M8, E-mail: ryanren528@gmail.com

2 Associate Professor, Department of Building, Civil, and Environmental Engineering, Concordia University, Montreal, Canada, E-mail: zhenhua.zhu@concordia.ca

3 Professor, Department of Building, Civil, and Environmental Engineering, Concordia University, Montreal, Canada, H3G 1M8, E-mail: zhi.chen@concordia.ca 
governmental regulations with respect to the development of sustainable construction have been promulgated. For example, USEPA proclaims regulations for non-road diesel engines to control the emissions from construction processes (USEPA 2004). U.S. Green Building Council (USGBC) developed the program of Leadership in Energy and Environmental Design (LEED) to facilitate the sustainability development of buildings and infrastructures. However, it is still challenging to monitor pollutant emissions during construction operations.

Enhancing the operational efficiency of construction equipment is a primary way to reduce the air pollutant emissions generated from construction operations (Tam et al. 2006; Ahn and Lee 2013). Operational efficiency of construction equipment is defined as the ratio of non-idle activity time to total activity time including idle time (Lewis et al. 2011). It could be used to analyze the productive and non-productive time, as well as to measure the equipment energy consumptions. It helps construction practitioners understand and control the equipment air pollutant emissions in construction operations.

Traditionally, the OEE monitoring and measurement are heavily dependent on the practitioners' observations, which is labour-intensive and time-consuming. On the other hand, a plethora of research efforts based on discrete-event simulation (DES) have been conducted to predict the equipment OEE in the planning stage. However, the estimated results are not always satisfactory, since the simulation does not fully reflect the real operating conditions all the time. Therefore, the environmental impacts caused by construction operations could not be revealed in real-time and accurate manner.

The main objective of the study is to present a novel method with the fusion of visual and thermal data to monitor the operating equipment efficiency in an automatic, accurate and real-time manner. Under the method, the construction equipment of interest is first localized and tracked in both video and thermal data. Then, the valuable operating time of the construction equipment is determined by estimating the duration of its value-added construction activity. In addition, the equipment total operating time is determined by counting the duration of the equipment with the running engine. This way, the OEE can be measured as the ratio of the valuable operating time over the total operating time. After the acquisition of OEE, the quantities of air pollutant emissions from the equipment can be computed using the emissions models. The method has been tested on a real construction site of Poste De Lorimier in Montreal, Canada. Both high definition digital camera and thermal camera were placed at the jobsite to record the construction activities. The test results indicate the effectiveness of the proposed method.

\section{BACKGROUND}

So far, there are several research efforts that have been conducted to investigate the potential air pollutant emissions caused by construction operations. These studies can be classified into two categories: 1) estimate air pollutant emissions; 2) monitor diesel exhaust emissions. In this context, a comprehensive review of existing research studies that have been conducted to estimate and monitor air pollutant emissions from construction equipment is presented.

\subsection{Estimating Air Pollutant Emissions}


The estimation of pollutant emissions from equipment were investigated based on its engine dynamometers or by the simulation of the overall construction process. They can be generally divided into two categories: estimation emissions 1) at the equipment level and 2) at the project level. The emission estimation methods at both levels are presented in the following section.

\subsubsection{Emission Estimation at the Equipment Level}

The fuel-use and emission rate of construction equipment is considered as a fundamental parameter to predict emissions from construction equipment. Therefore, several widelyused estimation models were employed to quantify diesel exhausts from construction equipment. Specifically, the NONROAD model is to predict emissions from non-road equipment, including construction, mining, industrial equipment and so on (USEPA 2005). Similarly, the Urban Emissions Model (URBEMIS) is a comprehensive estimation model for off-road vehicle emissions incorporating the California Air Resources Board's Emission Factors (EMFAC) 2007 model and the OFFROAD 2007 model. Although the emission estimation models can effectively develop the emission inventory, it is limited to assess the potential impacts of onsite activities. Specifically, the emission factors of emission models can not represent the real-world operating conditions. Besides, the estimation models do not take into account the fuel use and emissions during construction operating.

\subsubsection{Emission Estimation at the Project Level}

Several studies have been conducted based on the life-cycle assessment (LCA) method to analyze the potential environmental impacts of construction processes. For example, Cass and Mukherjee (2011) employed a hybrid LCA approach to compute the quantities of Greenhouse Gas (GHG) generated from highway construction operations and onsite and to-site transportation. Bilec et al. (2010) conducted a study to holistically analyze and assess the environmental impacts produced from the construction phase of commercial buildings using the LCA method. However, the possible planning changes during construction operations are significantly neglected, which are common in the construction industry. Consequently, the potential environmental impacts caused by construction projects are underestimated.

In addition, discrete-event simulation (DES) method was employed to predict he construction equipment utilization and the corresponding air pollutant emissions. For instance, Zhang (2014) developed a DES model to predict emissions of two excavators, ten off-road trucks and one dozer in the earthmoving operations. Ahn et al. (2010) adopted the DES model to predict the construction equipment utilization and the air pollutant emissions in a tunnel project. These studies revealed the DES method was able to the estimate pollutant emissions and operational efficiency of each piece of equipment during construction operations. However, the estimated emission quantities and the operational efficiency could not reflect the real operating conditions due to the constant changing and complex nature of construction environment.

\subsection{Monitoring Air Pollutant Emissions}

The portable emission measurement system (PEMS) is the most direct means of collecting the exhaust emissions from in-use construction equipment (Frey et al. 2010). The PEMS is connected with the tailpipe of the operating equipment to measure emission pollutants $(\mathrm{CO} 2$, 
NOx, PM etc.). The testing results can be used to not only facilitate the emission inventory, but also to assess the environmental impacts of the real-world construction activities. However, the biggest limitations of the deployment of PEMS is the pricey expense of the instrument including the purchase price and maintenance fares. In an addition, the PEMS is sensitive to the weather conditions and operating conditions. In hence, it is challenging to monitor exhaust emissions using PEMS on construction jobsites.

Thus, electromechanical accelerometers are employed to monitor the equipment usage and its operational efficiency through identifying the modes of the equipment. Specifically, the accelerometer is used to measure the acceleration forces on 3 axes (X, Y and $\mathrm{Z}$ ). Then, the idle and non-idle modes of the equipment of interest can be determined. Such way, the OEE can be computed. The feasibility of the accelerometer-based method was tested based on a threshold-based scheme of the acceleration signal energy (Ahn et al. 2012). However, the determination of threshold values must be based on construction scenarios. The threshold value would be different if the equipment is working under different construction scenarios. Therefore, the threshold value of each piece of equipment has to be defined separately. Similarly, Global Positioning Systems (GPS) are employed to monitor the movement of construction equipment. Then, the air pollutant emissions from operating equipment can be estimated. However, the GPS-based method cannot report the emissions of the construction equipment under the stationary operations.

\section{OBEJECTIVE AND PROPOESED FRAMEWORK}

The main objective of this study is to develop a method of automatically monitoring the operating equipment efficiency for the purpose of reduction of air pollutant emissions. In order to accomplish the goal, a novel method based on the fusion of vision-based tracking techniques with the thermal imaging technology is proposed. The study is expected to provide construction practitioners with the method of measuring the OEE in an automatic, accurate and cost-effective manner.

The proposed method consists of two main components: identification of valuable operating time and determination of idling time when the engine is on/off. The OEE results will be integrated into an existing mathematical model to quantify the air emissions generated from the construction equipment. The overall framework of the proposed method is described in Figure 1.

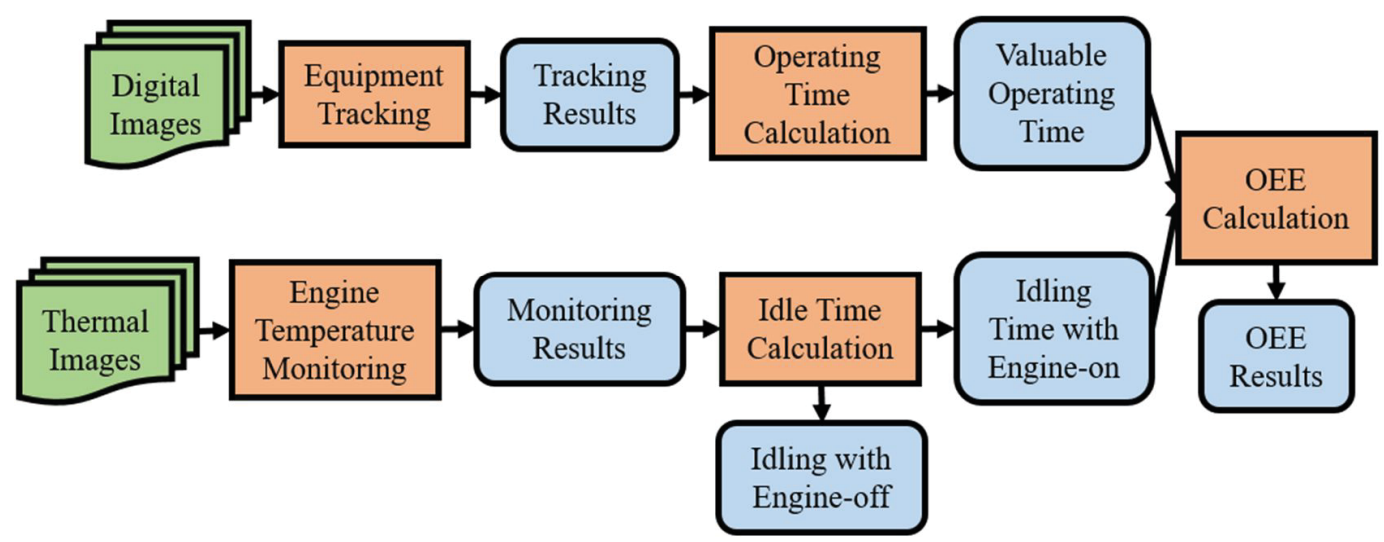

Figure 1: Flowchart of the proposed method 
The particle filtering-based tracking method is adopted to track the construction equipment in videos. Its effectiveness in tracking entities under the conditions of occlusions and clutters has been tested in the study of Zhu et al. (2016). The valuable operating time is identified by counting the tracking results where the equipment is conducting value-added activities (e.g. loading and hauling). Meanwhile, the thermal camera is employed to monitor the temperature conditions of the equipment engine, since the thermal camera can capture the heat information generated from the running engine. Accordingly, the idling time when the equipment engine is on/off is distinguished by comparing the temperature with the thermographic temperature scale. The idling time when the engine is off is deducted. Following that, the operating equipment efficiency can be computed by the ratio of the valuable operating time to the sum of valuable operating time and idling time with running engine.

\section{4}

\section{IMPLEMENTATION AND RESULTS}

\subsection{Implementation and Project Background}

The proposed method has been implemented as a prototype in the environment of Matlab R2015a. The method was tested in a 64-bit operating system, Microsoft Windows 7 Enterprise. The hardware configuration consists of an Intel® Core-i7-4770 CPU @3.40 GHz and 8 gigabytes memory, and an NVIDIA Quadro 600 GPU (graphic processing unit).

In order to test the feasibility and effectiveness of the proposed method, a high definition camera and a thermal camera were placed at the jobsite, Poste De Lorimier in Montreal funded by Hydro-Quebec, to record the jobsite activities. The Poste De Lorimier project is going to build a transformer substation with $315 / 25 \mathrm{KV}$, and to place two $315-\mathrm{KV}$ underground lines of $7 \mathrm{~km}$ to connect the new Lorimier substation to other substations.

\subsection{Results}

The high definition camera Nikon D600 was statically placed at the jobsite to record construction activities. The video resolution was 1920 * 1080 with 25 frame per second. Meanwhile, a thermal camera (Zenmuse XT, FLIR) was adopted to monitor construction equipment. The thermal camera was set up to capture images with the resolution 640 * 512 . The construction activity of interest was an earthmoving operation performed in an open field. There were one backhoe and one tipper truck involved in the operation, as shown in Figure 2. The monitoring was conducted for around 16 minutes, during which time the backhoe was not turned off.

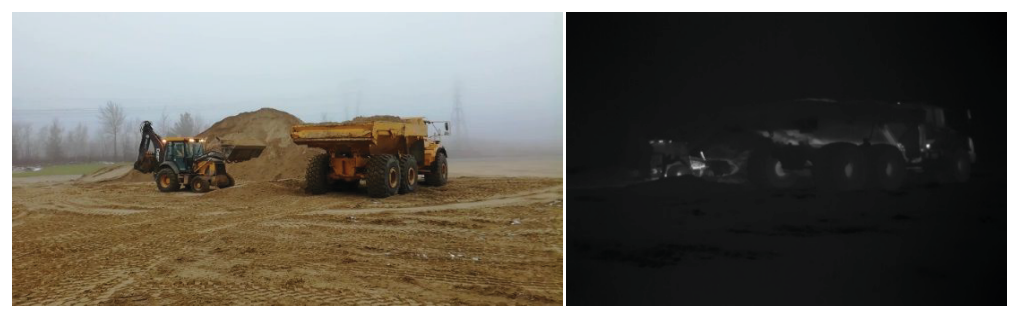

Figure 2: Examples of digital and thermal image

Figure 3 depicts the results of thermal image analysis. The temperature scale bar is presented at the right side of the image, which indicates the temperature ranges from 
maximum temperature to minimum temperature in the image. Specifically, the higher temperatures are represented with the bright colour (yellow and orange), while the lower temperatures are delineated by dark colour (purple and blue). Obviously, the running engines of construction equipment generated heat during the operation. Therefore, the temperatures of equipment engines were brighter than those of the background and materials. Based on the colour difference, the running engine can be easily distinguished. As shown in Figure 3, the engine and the tailpipe of the backhoe were represented with the pink and yellow color.

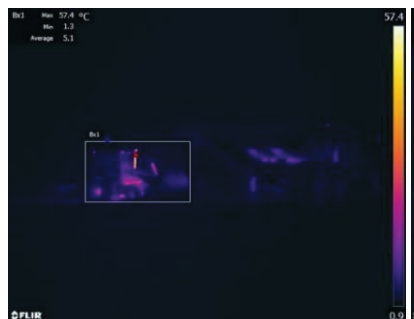

Frame 005

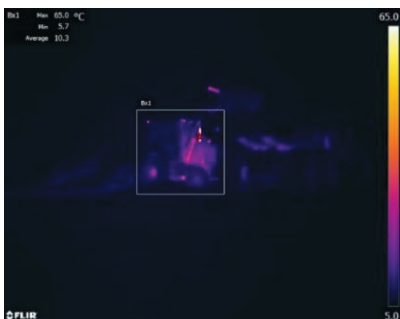

Frame 065

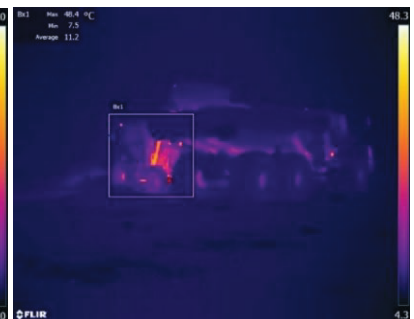

Frame 125

Figure 3: Results of thermal image analysis

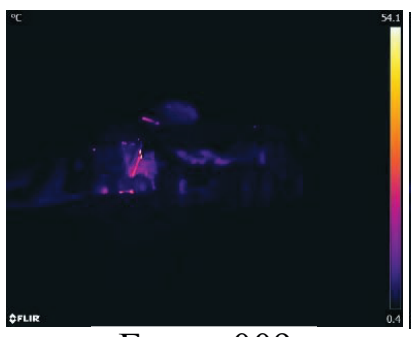

Frame 009

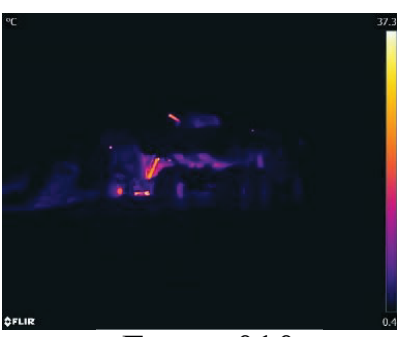

Frame 010

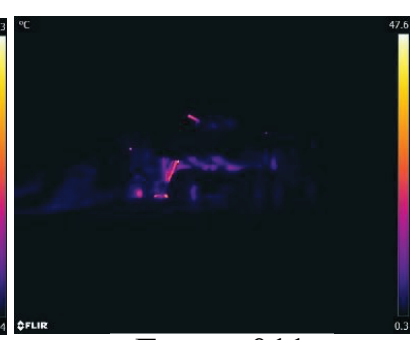

Frame 011

Figure 4: Results of thermal image analysis

Figure 5 depicts the temperature trends of the entire video sequence. It is manifest that there were big fluctuations of engine temperature during the operating process. The main reason of this phenomenon is because of the occlusions, as shown in Figure 4. The backhoe engine was gradually occluded by the truck when the backhoe was being driven towards the truck for loading. Then, the temperature of the monitoring results declined, since the engine was the main heat source which was occluded. When the backhoe returned to the view of the thermal camera, the temperature of monitoring results increased.

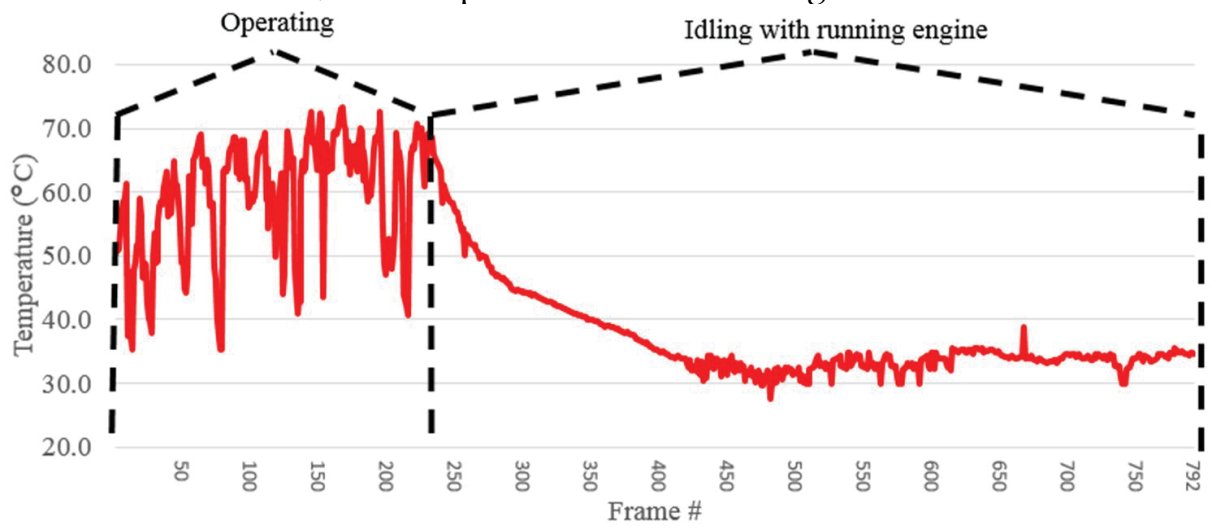

Figure 5: Temperature trends of the backhoe 
Figure 6 illustrates the tracking results of the backhoe. As shown in Table 1, the time span of each equipment mode is depicted. Accordingly, the operating equipment efficiency can be calculated. After the acquisition of OEE, the emissions generated from the backhoe can be quantified using the OEE-based emission models.

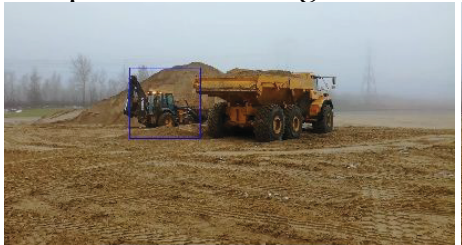

Frame 4000

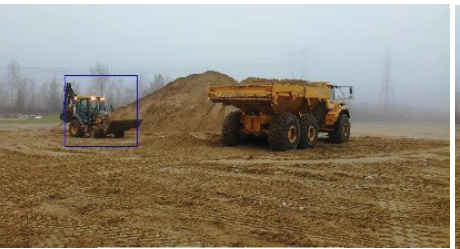

Frame 4200

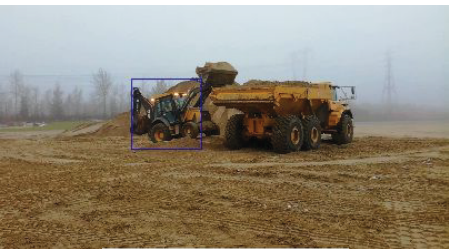

Frame 4400

Figure 6: Tracking results of the backhoe

Table 1: Time period of each mode

\begin{tabular}{lc}
\hline \multicolumn{1}{c}{ Mode } & Time \\
\hline A. Operating & 226 seconds \\
B. Idling with engine on & 566 seconds \\
C. Idling with engine off & 0 \\
\hline OEE $(\mathrm{A} / \mathrm{A}+\mathrm{B})$ & $28.5 \%$ \\
\hline
\end{tabular}

\section{DISSCUSION}

The proposed method with the fusion of vision-based method and thermal imaging monitoring can be used to measure the OEE in an effective and timely manner. Based on the monitoring results, the potential harmful effects on the workforces' safety and air quality could be identified in/near real-time. Also, construction professionals could identify which equipment is the most emission source during operations and propose alternative plans to mitigate the pollutions. Even though the estimation models can predict the approximate emission level caused by the entire construction processes, they cannot provide practitioners with the prompt feedbacks with respect to the potential harmful effects in a certain operating period. In addition, the proposed method is more cost-effective in comparison with the PEMS-based or sensor-based methods. Specifically, the cost of PEMS is up to $\$ 10,000$, which is the biggest obstruction. Although the price of the sensor (accelerometer and GPS) is acceptable (less than \$ 500), it is still not practical to install the sensor to each piece of equipment for the large-scale construction project. Therefore, the proposed method is applicable and practical to monitor the operating equipment efficiency for the purpose of pollutant emission reduction. Admittedly, the proposed method would be deficient when the equipment of interest is fully occluded for a long time or it leaves the view of cameras. In such situation, the tracking target will be lost. In order to mitigate this issue, it is recommended to place both video and thermal cameras at height to monitor the equipment with the better coverage.

\section{CONCLUSION AND FUTURE WORK}

The operating equipment efficiency indicates the efficient employment of construction equipment during the operations, which is considered as a primary way to control air 
pollutant emissions from diesel-based engines. A novel method based on the integration of videos and thermal images is presented to monitor the operating equipment efficiency. The preliminary results showed the potential of thermal cameras for monitoring the equipment engine temperature in construction scenarios. Future work will be focused on the effectiveness test of engine temperature monitoring in different meteorological conditions. It is mainly because the temperature generated by the equipment engine can be easier released to the cold atmosphere than that is released to hot atmosphere. This would influence the determination of idling time with/without the running engine due to the transient mode between idling with running engine and idling with engine off.

\section{REFERENCES}

Ahn, C. and Lee, S. (2013). Importance of Operational Efficiency to Achieve Energy Efficiency and Exhaust Emission Reduction of Construction Operations. J. Constr. Eng. Manage., 10.1061/(ASCE)CO.1943-7862.0000609, 404-413.

Ahn, C. R., Lee, S. H., and Peña-Mora, F. (2012). Monitoring system for operational efficiency and environmental performance of construction operations, using vibration signal analysis. Proc., Construction Research Congress, American Society of Civil Engineers, Reston, VA.

Bilec, M., Ries, R. and Matthews, H. S. (2010). Life-cycle assessment modeling of construction processes for buildings. J. Infrastruct. Syst., 16(3), 199-205.

Cass, D., and Mukherjee, A. (2011). Calculation of greenhouse gas emissions for highway construction operations using a hybrid life cycle assessment approach: A case study for pavement operations. J. Constr. Eng. Manage., 137(11), 1015-1025.

Frey, H. C., Rasdorf, W. and Lewis, P. (2010). Results of a comprehensive field study of fuel use and emissions of nonroad diesel construction equipment. Transportation Research Record 2158, Transportation Research Board, NRC, Washington, DC.

Lewis, P., Leming, M., Frey, H. C. and Rasdorf, W. (2011). Assessing the effects of operational efficiency on pollutant emissions of nonroad diesel construction equipment. TRB 11-3186, Proc., 90th Annual Meeting of the Transportation Research Board, Transportation Research Board, Washington, DC.

Lewis, P., Leming, M. and Rasdorf, W. (2011). Impact of engine idling on fuel use and CO2 emissions of nonroad diesel construction equipment. J. Manage. Eng., 28, 31-38.

Tam, V. W. Y., Tam, C. M., Shen, L. Y., Zeng, S. X. and Ho, C. M. (2006) Environmental performance assessment: Perceptions of project managers on the relationship between operational and environmental performance indicators. Constr. Manage. Econ., 24(6), 287-299.

U.S. EPA. (2004). Exhaust and Crankcase Emission Factors for Nonroad Engine Modeling Compression Ignition, EPA420-P-04-009, U.S. EPA, Washington, DC.

U.S. EPA. (2005). "Clean air non-road diesel rule summary.” EPA-420-F-04-029, Ann Arbor, Mich.

U.S. EPA. (2008). Direct emissions from mobile combustion sources. Climate leaders greenhouse gas inventory protocol core module guidance, EPA430-K-08-004, Office of Air and Radiation, Ann Arbor, MI.

Zhu, Z., Ren, X. and Chen, Z. (2016). Visual Tracking of Construction Jobsite Workforce and Equipment with Particle Filtering. J. Comput. Civ. Eng., 10.1061/(ASCE)CP.19435487.0000573, 04016023. 